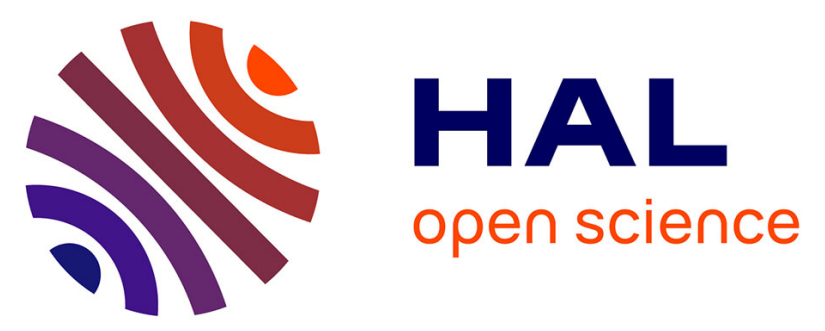

\title{
RECENT PROGRESS ON THE MEASUREMENT OF ABSOLUTE ATOMIC PHOTOIONIZATION CROSS SECTIONS
}

\author{
J. Samson, L. Lyn, G. Haddad, G. Angel
}

\section{- To cite this version:}

J. Samson, L. Lyn, G. Haddad, G. Angel. RECENT PROGRESS ON THE MEASUREMENT OF ABSOLUTE ATOMIC PHOTOIONIZATION CROSS SECTIONS. Journal de Physique IV Proceedings, 1991, 01 (C1), pp.C1-99-C1-107. 10.1051/jp4:1991113 . jpa-00249751

HAL Id: jpa-00249751

https://hal.science/jpa-00249751

Submitted on 1 Jan 1991

HAL is a multi-disciplinary open access archive for the deposit and dissemination of scientific research documents, whether they are published or not. The documents may come from teaching and research institutions in France or abroad, or from public or private research centers.
L'archive ouverte pluridisciplinaire HAL, est destinée au dépôt et à la diffusion de documents scientifiques de niveau recherche, publiés ou non, émanant des établissements d'enseignement et de recherche français ou étrangers, des laboratoires publics ou privés. 


\title{
RECENT PROGRESS ON THE MEASUREMENT OF ABSOLUTE ATOMIC PHOTOIONIZATION CROSS SECTIONS
}

\author{
J.A.R. SAMSON, I. LYN(1), G.N. HADDAD(2) and G.C. ANGEL (3) \\ Behlen Laboratory of Physics, University of Nebraska Lincoln, NE 68588 , \\ U.S.A.
}

\begin{abstract}
Recent measurements of the photoionization cross sections of $O$, $N$, and $C l$ are reviewed and new data are presented for $\mathrm{Ne}, \mathrm{Ar}, \mathrm{Kr}$, and $\mathrm{Xe}$. These latter results are compared with theory and reveal areas of important disagreement.
\end{abstract}

\section{1 - INTRODUCTION}

Measurements of the absolute photoionization cross sections of most atoms, with the exception of the rare gases, is difficult because of the problem in measuring the absolute number density of the absorbing gas or vapor. However, it is possible to measure accurate relative cross sections provided we can measure the absolute or relative intensity of the incident radiation. Such measurements of the intensity of the incident radiation usually depend on knowing the absolute cross sections of the rare gases $/ 1,2$ I

In certain cases the relative cross section can be placed on an absolute basis if the atoms form stable dimers (eg. $\mathrm{O}_{2}, \mathrm{~N}_{2}, \mathrm{Cl}_{2}$, etc). This is achieved by measuring the absolute cross section of the molecule in the spectral region between about 50 to $200 \AA$. To a good approximation the atomic cross section is simply one half of the molecular cross section. If the relative atomic cross section measurements overlap this region they can be normalized to one-half of the molecular value.

A second technique is to normalize the relative continuum oscillator strength to the value expected from the Thomas-Kuhn sum rule. A third method is to normalize the relative data to the semi-emperical atomic cross sections tabulated by Henke et al. $/ 3 /$. Each of these techniques requires the relative data to be measured over an extended energy range. The basic technique to measure relative cross sections is to use a mass spectrometer to isolate the atom of interest and measure the ratio of ions produced/incident photon. At the low pressures used this ratio is proportional to the photoionization cross section.

During the last five years cross sectional measurements have been made for $0 / 4,5 /$, Cl $/ 6 /$ and $\mathrm{N}$ /unpublished/ by use of the above techniques. In addition, precision measurements of the absolute cross sections of the rare gases have been made $/ 7 /$. The results of these measurements are discussed below.

2 - ABSOLUTE CROSS SECTIONS (O, N, AND Cl)

The experimental photoionization cross sections for $\mathrm{N}$, ranging from threshold to the K-edge, are shown in Fig. 1. The relative data had to be taken in two sections, first with a normal

(1) Present address: Shanghai Institute of Optics and Fine Mechanics, Academia Sinica, P.O. Box 8211, Shanghai, P.R. of China.

(2) Present address: National Measurement Laboratory, CSIRO Division of Applied Physics, P.0. Box 218, Lindfield, NSW 2070, Australia.

(3) Present address: Eaton Corp. Beverly, MA 01915. 


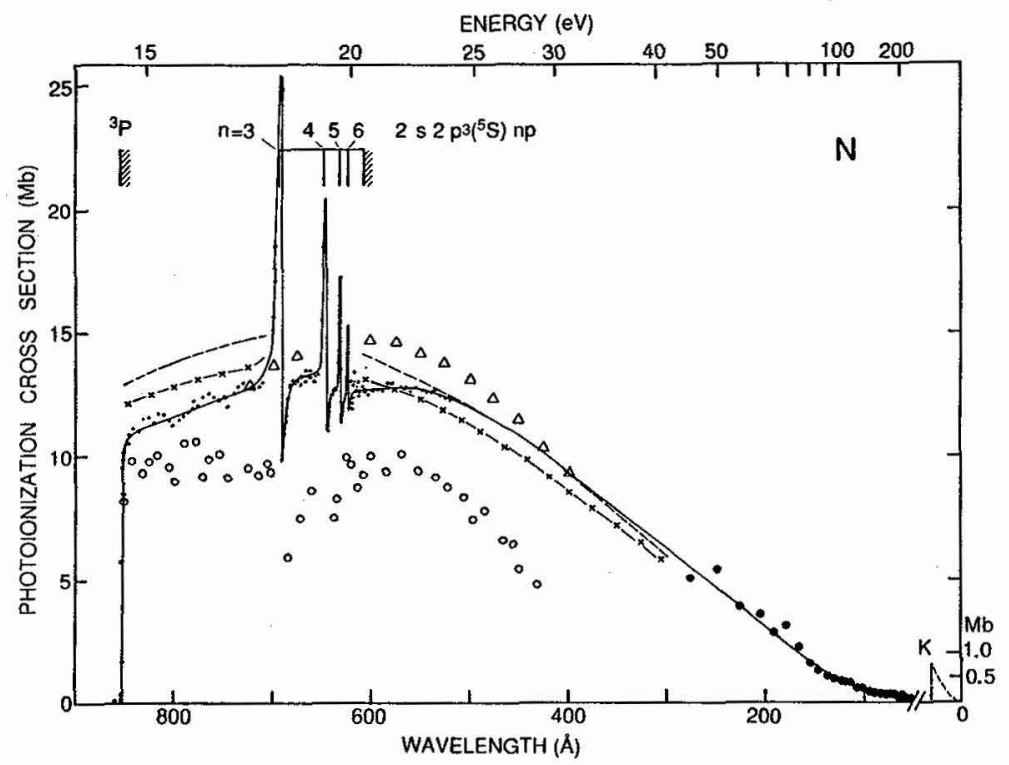

Fig. 1 - Photoionization cross section of atomic nitrogen. Present results are shown by the small and large closed data points. The solid Iine indicates the smoothed experimental values. $\triangle$, Ehler (ref. 9); 0 , Comes (ref. 10); - (length), $-x-x^{-}$(velocity), Le Dourneuf (ref. 8).

incidence monochromator (small solid data points) and then with a grazing incidence monochromator (large solid data points). The short wavelength data were normalized to onehalf of the molecular cross section. The long wavelength data were adjusted to give a smooth fit to the extrapolated short wavelength data (solid line). Because the extrapolated data covers a span of about $200 \AA$ the threshold data could easily be located within about $\pm 10 \%$ of its present position. However, the present choice was influenced with its agreement with the calculated values (dipole length) of Le Dourneuf et al. /8/. The early experimental data of Ehler and Weissler $/ 9 /$ and Comes and Elzer /10/ are also shown in Fig. 1.

To illustrate the reliability of the normalization procedure we show, in Fig. 2, our normalized data along with the cross section of atomic nitrogen $\sigma(\mathrm{N})$, obtained by equating $\sigma(\mathrm{N})$ to the value of one-half $\sigma\left(\mathrm{N}_{2}\right)$ and to the value $\left[\sigma\left(\mathrm{NH}_{3}\right)-3 \sigma(\mathrm{H})\right]$. The tabulated data of Henke et al. $/ 3 /$ and the experimental data of Denne $/ 11 /$ are also shown. The solid line represents the curve $\sigma(N)=C^{-m}$, where $E$ is the incident photon energy and $C$ and $m$ are constants selected to give a good fit to the experimental data. This illustrates the hydrogenic nature of the cross section for photon energies greater than $60 \mathrm{eV}$. The theoretical data of Le Dourneuf et al. are included in this Figure to show their close agreement with the experimental results. The dashed line is an estimate of the true $\sigma(N)$ value at lower photon energies.

Figure 3 shows our $1985 / 4 /$ and $1988 / 5 /$ photoionization cross sections for 0 along with the total cross sections of Kohl et al. $/ 12 /$ and Comes et al. $/ 13 /$. Partial cross sectional data of several groups are also included /14-16/. Our latest data reproduces the broad peak observed earlier in the $2 \mathrm{P}$ continuum (in the vicinity of $19 \mathrm{eV}$ ). This result is in disagreement with most theoretical data. Another source of disagreement with theory occurs at the ionization threshold. Several groups $117-19 /$, using the R-matrix technique or variations of this method, calculate a threshold value of $4 \mathrm{Mb}$ for the cross section, whereas, our latest data indicates a value of about $3 \mathrm{Mb}$. This discrepency is as yet unresolved.

The autoionizing structure caused by the $2 \mathrm{~s} 2 \mathrm{p}^{4} \mathrm{np}$ Rydberg series has recently been studied by Krause et al. $/ 20 /$ using photoelectron spectroscopy techniques. Their results show that strong autoionization occurs in each of the ${ }^{4} \mathrm{~S}, 2 \mathrm{D}$, and $2 \mathrm{P}$ continua. 


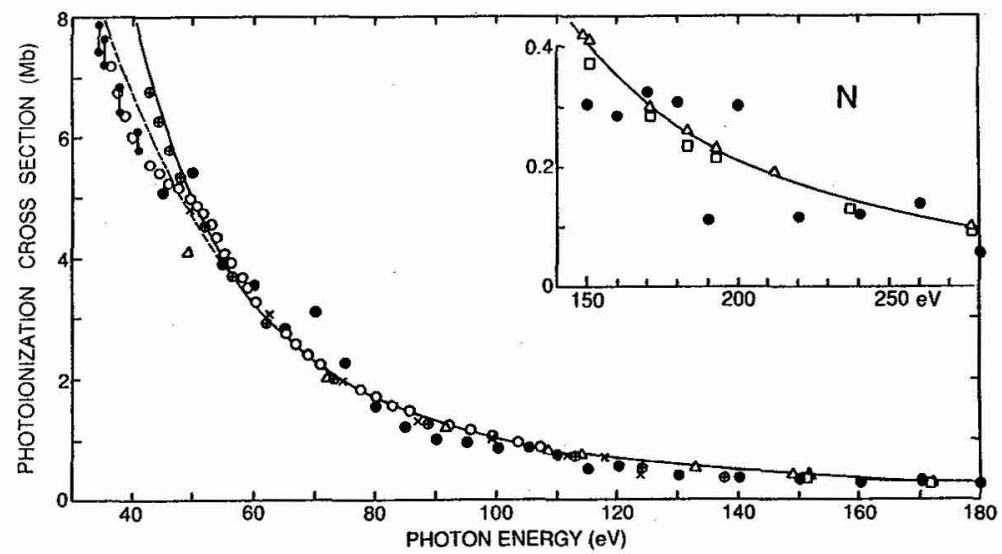

Fig. 2 - Photoionziation cross section of atomic nitrogen. - Present data (normi : ized); 0 , from $1 / 2 \sigma\left(\mathrm{N}_{2}\right) ; \boldsymbol{0}$, from $\sigma\left(\mathrm{NH}_{3}\right)-3 \sigma(\mathrm{H}) ; \boldsymbol{a}$. Denne (ref. 11); $\Delta$, Henke (ref. 3); $\boldsymbol{\&}$, Le Dourneuf (ref. 8).

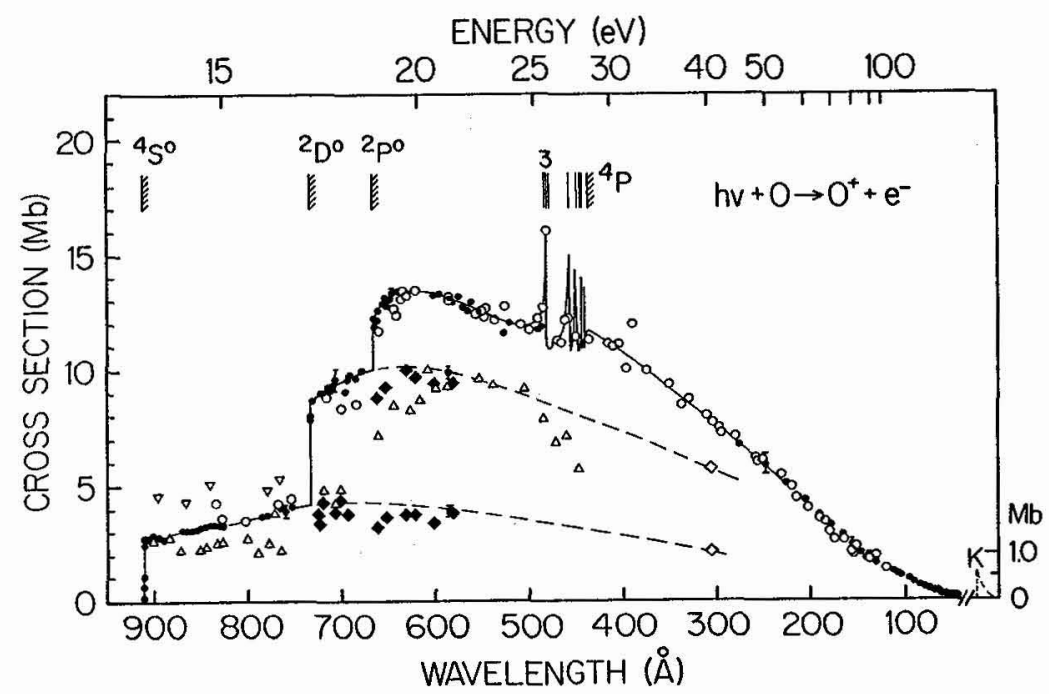

Fig. 3 - Photoionization cross section of atomic oxygen. 0 (1985) and (1988), Samson (refs. 4,5); $\nabla$, Kohl (ref. 12); $\Delta$, Comes (ref. 13). Partial cross sections; (ref. 14); 0 , Dehmer (ref. 15); $\boldsymbol{\Phi}$, Samson (ref. 16). 
Figures 4 and 5 show the absolute photoionization cross sections of atomic chlorine /6/ compared to several theoretical results /21-26/. There is generally good agreement between theory and experiment at the higher photon energies. However, the various theoretical results differ seriously between each other and with the experimental results near threshold $115-21 \mathrm{eV})$.

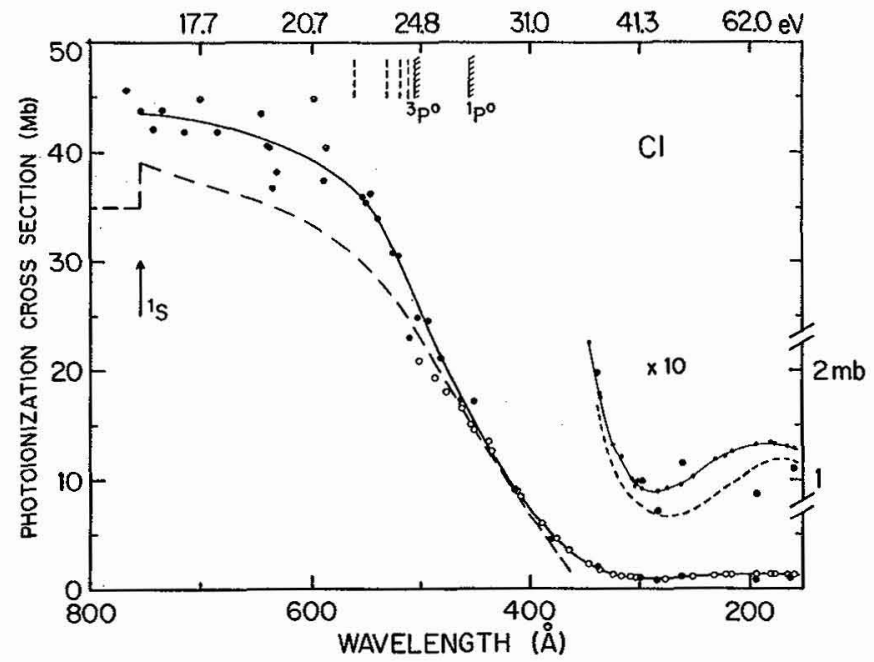

Fig. 4 - Photoionization cross section of atomic chlorine. (normalized), 0 and -1 rom $1 / 2$ $\sigma(\mathrm{Cl} 2)$, Samson ref. 6); - - Cherepkov, et al. (ref. 21); --..-, Yarzhemsky, et al. (ref. 22).

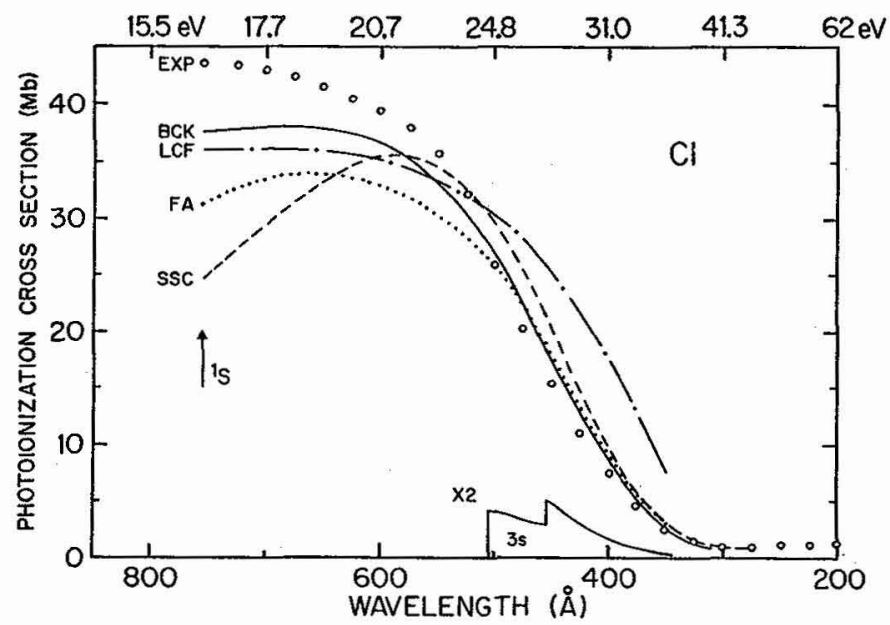

Fig 5 - Photoionization cross section of atomic chlorine. 0 , smoothed experimental data, Samson (ref. 6); - Brown, et al. (ref. 24); - - - - Lamoureux, et al. (ref. 23); .... Fielder, et al. (ref. 25); - - -, Shahabi, et al. (ref. 26). 


\section{3 - ABSOLUTE CROSS SECTIONS ( $\mathrm{Ne}, \mathrm{Ar}, \mathrm{Kr}$, and $\mathrm{Xe}$ )}

Accurate values of the photoionization cross sections of the rare gases are very important because they provide a standard to test the validity of the various theoretical results. However, if we compare the calculations using the Relativistic Random Phase Approximation (RRPA) $/ 27,28 /$ with the tabulated recommended experimental values $/ 29,30 /$ we see significant deviations in certain spectral regions. These vary from a few percent to $150 \%$. This has prompted us to make new precision measurements to an accuracy of $1 \%$ or less. Details of the experimental techniques have been published $/ 7 /$. The precision cross sectional measurements for $\mathrm{Ne}, \mathrm{Ar}, \mathrm{Kr}$, and $\mathrm{Xe}$, along with some unpublished data with a $\pm 3 \%$ accuracy, are presented in Figs. 6-12 and compared with the RRPA results of Huang et al. $128 \%$. We have also included the experimental data of Watson /31/ and Lang and Watson /32/ who quote an accuracy of $\pm 3 \%$. We are in excellent agreement with their results, for $\mathrm{Ne}$ and $\mathrm{Ar}$ but for $\mathrm{Kr}$ and $\mathrm{Xe}$ our respective data fall outside of the quoted error limits.

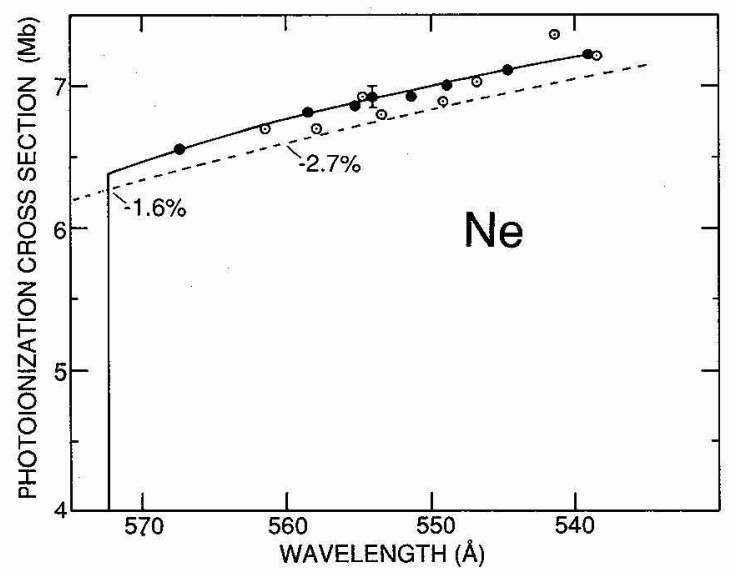

Fig. 6 - Photoionization cross section of Ne. $\odot( \pm 5 \%)$, Samson (ref. 2$) ; \bullet( \pm 3 \%)$, present data; - - , Marr and West (ref. 29).

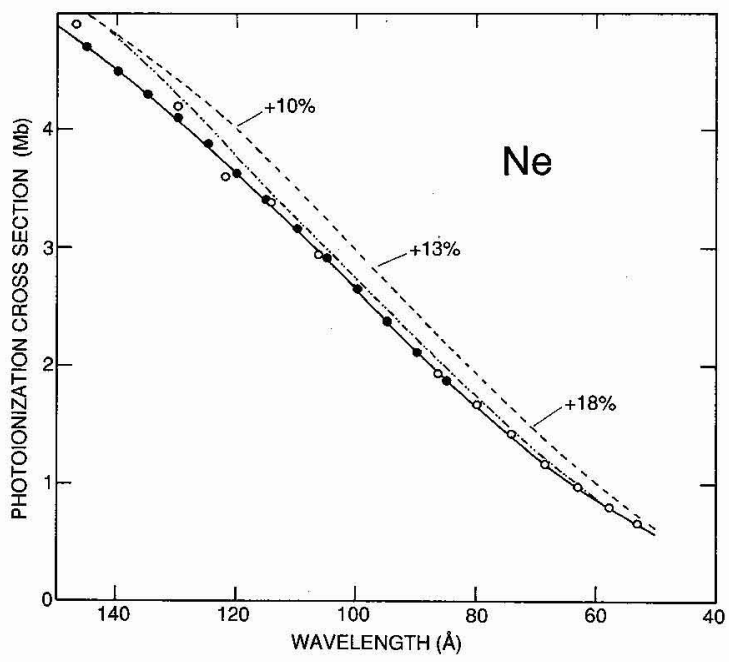

Fig. 7 - Photoionization cross section of Ne.

$( \pm 3 \%)$, present data; 0 , Jatson (ref. 31);

-.-, Marr and West (ref. 29); -..., Huang, et al. (ref. 28). 


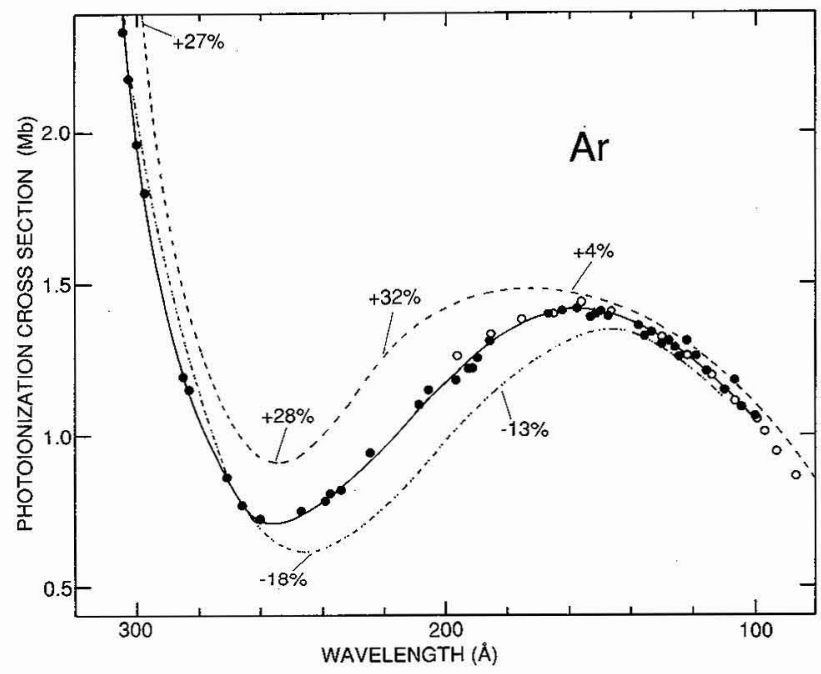

Fig. 8 - Photoionization cross section of Ar. $( \pm 3 \%)$, present data; 0 , Watson (ref. 31 ); -.-, Marr and West (ref. 29); - ...-..., Huang et al. (ref. 28).

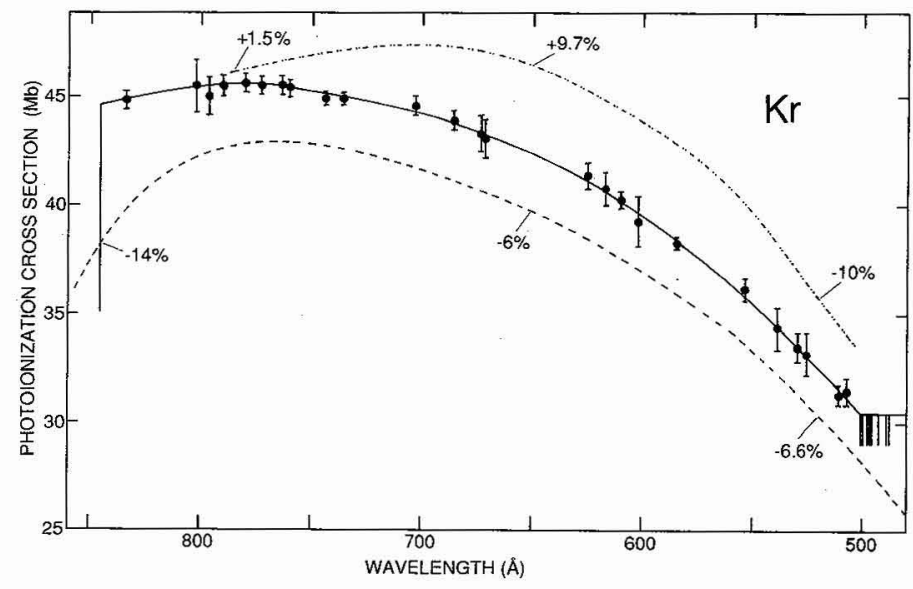

Fig. 9 - Photoionization cross section of $\mathrm{Kr}$. $(0.8$ to $3 \%)$, present data; - - Marr and West (ref. 29); -...- Huang et al. (ref. 28). 


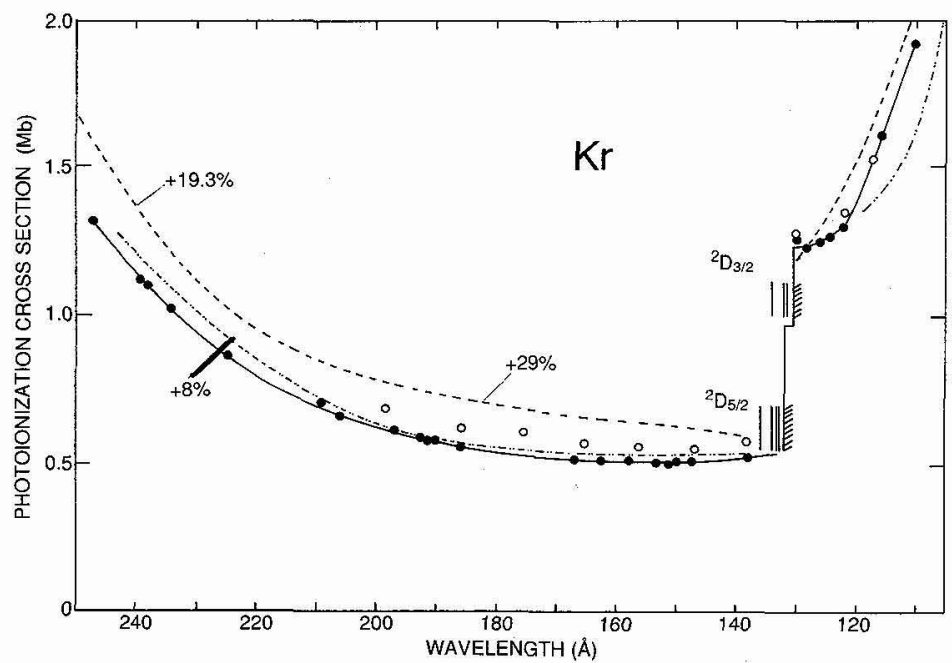

Fig. 10 - Photoionization cross section of $\mathrm{Kr}$. $( \pm 3 \%)$, present data; o, Lang and Watson (ref. 32); ---, Marr and West (ref. 29); -..-.-, Huang, et al. (ref. 28 ).

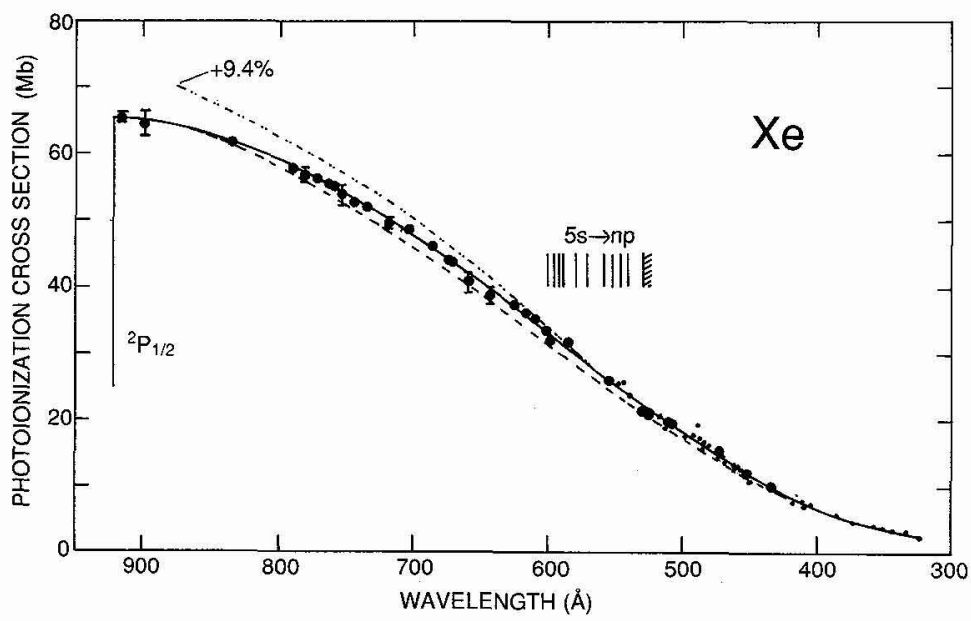




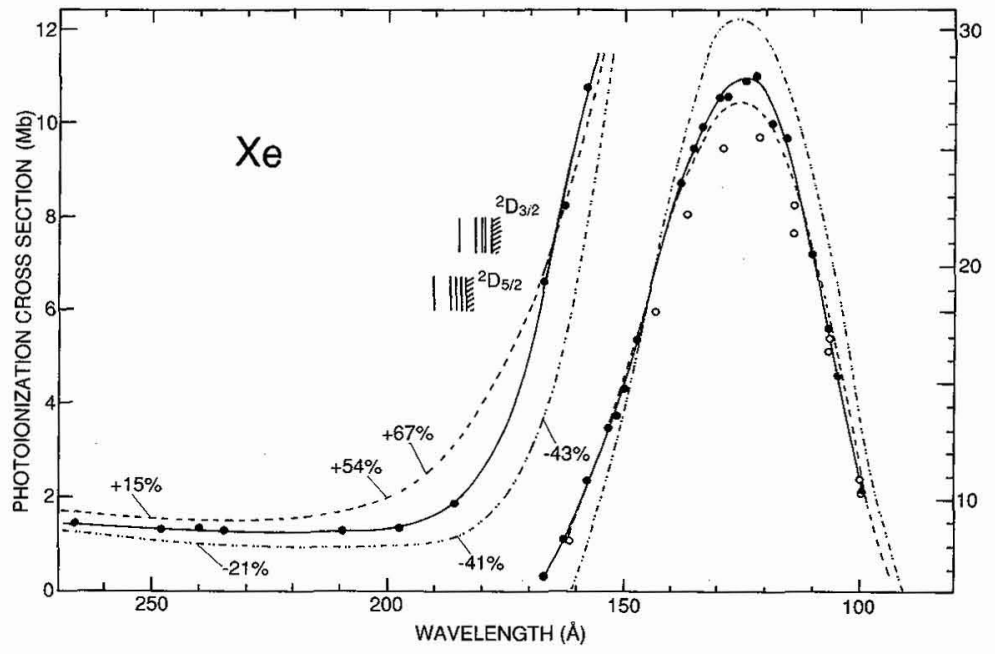

Fig. 12 - Photoionization cross sections of Xe.

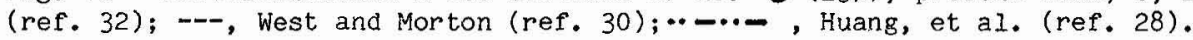

In general, our new results bring the experimental and theoretical results closer together. However, there are still some substantial deviations, as can be seen in the Figures. The \pm percent values shown in the Figures represent the deviation above $(+)$ or below $(-)$ our new data for both the calculated data and the tabulated experimental data.

We are continuing our precision measurements to further reduce the experimental uncertainties. However, it would appear worthwhile to have further theoretical studies performed.

4 - ACKNOWLEDGMENTS

This work was supported by the National Science Foundation (NSF) under Grant Nos. PHYS -8803911 and ATM-8617670.

\section{REFERENCES}

$11 /$ Samson, J.A.R., J. Opt. Soc. Am. 54 (1964) 6.

/2/ Samson, J.A.R., in Advances in Atomic and Molecular Physics, eds. D.R. Bates and I. Estermann (Academic Press, Inc. NY, 1966) Vol. 2, pp 177-261.

/3/ Henke, B.L., Lee, P., Tanaka, T.J., Shimabukuro, R.L., and Fujikawa, B.K., At. Data Nucl. Data Tables 27 (1982) 1.

14/ Samson, J.A.R. and Pareek, P.N., Phys. Rev. A 31 (1985) 1470.

15/ Angel, G.C. and Samson, J.A.R., Phys. Rev. A $3 \overline{8}$ (1988) 5578.

16/ Samson, J.A.R., Shefer, Y., and Ange1, G.C., Phys. Rev. Lett. 56 (1986) 2020.

/7/ Samson, J.A.R. and Yin, L., J. Opt. Soc. Am. B 6 (1989) 2326.

18/ Le Dourneuf, M., Lan, Vo. Ky., and Hibbert, A., J. Phys. B 9 (1976) L359.

19/ Ehler, A.W. and Weissler, G.L., J. Opt. Soc. Am. 45 (1955) 1035.

110/ Comes, F.J. and Elzer, A., Z. Naturforsch. 23a (1 $\overline{968}) 133$.

/11/ Denne, D.R., J. Phys. D 3 (1970) 1392. 
/12/ Kohl, J.L., Lafyatis, G.P. Palenius, H.P., and Parkinson, W.H.,. Phys. Rev. A 18 (1978) 571 .

113/ Comes, F.J., Speier, F., and Elzer, A., Z. Naturforsch. 23a (1968) 125.

114/ Hussein, M.I.A., Holland, D.M.P., Codling, K., Woodruff, P.R., and Ishiguro, E., J. Phys. B 18 (1985) 2827.

115/ Dehmer, J. and Dehmer, P.M., J. Chem. Phys. 67 (1977) 1782.

/16/ Samson, J.A.R. and Petrosky, V.E., Phys. Rev. A 9 (1974) 2449.

/17/ Taylor, K.T. and Burke, P.G., J. Phys. B $\underline{9}$ (1976) L353.

/18/ Pradhan, A.K., J. Phys. B 11 (1978) L729.

/19/ Saxon, R.P., Nesbet, R.K., and Noble, C.J., Phys. Rev. 39 (1989) 1156.

120/ Krause, M.0., (private communication).

121/ Cherepkov, N.A. and Chernysheva, L.V., Izv. Akad. Nauk. SSSR, Ser. Fiz. 41 (1977) 2518 [Bull. Acad. Sci. USSR, Phys. Ser. 41 (1977) 47].

/22/ Yarzhemsky, V.G., Nefedov, V.I., Amusia, M.Ya., Cherepkov, N.A., and Chernysheva, L.V., J. Electron Spectrosc. Relat. Phenom. 23 (1981) 175.

123/ Lamoureux, M. and Combet Farnoux, F., J. Phys. Par is 40 (1979) 545.

/24/ Brown, E.R., Carter, S.L., and Kelly, H.P., Phys. Rev. A 21 (1980) 1237.

125/ Fielder, W.R. and Armstrong, L., Phys. Rev. A 28 (1983) $2 \frac{118}{}$.

/26/ Shahabi, S., Starace, A.F., and Chang, T.N., Phys. Rev. A 30 (1984) 1819.

/27/ Johnson, W.R. and Cheng, K.T., Phys. Rev. A 20 (1979) 978.

/28/ Huang, K.-N., Johnson, W.R., and Cheng, K.T., At. Data Nucl. Data Tables 26 (1981) 33.

/29/ Marr, G.V. and West, J.B., At. Data Nucl. Data Tables 18 (1976) 497.

/30/ West, J.B. and Morton, J., At. Data Nucl. Data Tables $\overline{22}$ (1978) 103.

131/ Watson, W.S., J. Phys. B $\underline{5}$ (1972) 2292.

/32/ Lang, J. and Watson, W.S., J. Phys. B $\underline{8}$ (1975) L339. 